\title{
Severe Acute Respiratory Syndrome and Sport
}

\section{Facts and Fallacies}

\author{
Raymond C.H. So, ${ }^{1}$ Joshua Ko, ${ }^{2}$ Yvonne W.Y. Yuan, ${ }^{1}$ James J. Lam ${ }^{3}$ and Lobo Louie ${ }^{4}$ \\ 1 Sports Science Department, Hong Kong Sports Institute, Hong Kong \\ 2 Department of Orthopaedics and Traumatology, Pamela Youde Nethersole Eastern Hospital, \\ Hong Kong \\ 3 Centre for Orthopaedic Surgery, Hong Kong \\ 4 Department of Physical Education, Hong Kong Baptist University, Hong Kong
}

\section{Abstract}

Severe Acute Respiratory Syndrome (SARS) not only paralysed economic activities in SARS-affected cities, it also affected sporting activities. SARS was identified in Hong Kong in late February 2003 and the WHO issued a global alert on 12 March, 2003. The incubation period of SARS is usually 4-6 days and patients commonly present with high fever (temperature $>38^{\circ} \mathrm{C}$ ), dry cough, chills and rigor, dyspnoea and diarrhoea. Although a specific antiviral agent and vaccines for SARS are not available at the time of writing, a standard treatment protocol for SARS has been developed. The average mortality rate is about $16 \%$ in Hong Kong.

The coronavirus is a common pathogen for upper respiratory tract infection and is the most probable pathogen for SARS. Transmission methods may, therefore, be similar for both these infections. Transmission is possible when aerosolised viral particles come into contact with the susceptible host's mucous membrane, most commonly the nose, but also the mouth and eyes.

With appropriate preventive measures to avoid contact with virus, the probability of infection is minimal. Isolation of those who have had close contact with confirmed or suspected SARS patients and/or who have persistent fever will be the most effective and practical method of avoiding contact. Maintaining personal hygiene and frequent hand washing can also reduce the risk of infection. Using diluted bleach (1 part bleach in 99 parts water) to cleanse training areas and equipment is also recommended.

With proper event planning to conform with quarantine measures, special travel arrangements, facility sterilisation and use of venues with good ventilation and filtering systems, sport competition can still proceed. 
In early 2003, Severe Acute Respiratory Syndrome (SARS), swept through hospitals and communities in Hong Kong and subsequently to 32 other countries or regions. ${ }^{[1]}$ Initially, there was international panic as not much was known about SARS. Nevertheless, in just over 2 months following the first outbreak, there were more than ten books, hundreds of scientific articles and countless newspaper clippings being published in relation to SARS. This could be one of the new records in this 'age of information'. However, there are facts as well as fallacies in some of these publications.

SARS had a significant impact on the local healthcare system. It also affected sporting activities at all levels, from recreational to professional. There is always concern about the possibility of contagion among athletes and spectators in competitive sports. Many sports involve close contact and a major competition will usually draw a large crowd and may bring people from different countries together. This creates a situation that may enhance the risk of a contagious disease spreading locally and even globally. Not surprisingly, after the SARS outbreak, many international events including both contact and non-contact sports, which were originally scheduled in the first half of 2003, were cancelled or postponed. For example, the 4th FIFA Women's World Cup 2003 was postponed and transferred from China to the US. On March 30, the International Ice Hockey Federation announced the cancellation of the 2003 IIHF Women's World Championship, which had been scheduled for April in Beijing, China. Similarly, the World Track Cycling Championships, scheduled for the July/August period in Shenzhen, China were also cancelled. The 2003 Cathay Pacific Squash Open in Hong Kong, the 2nd Asian Archery Grand Prix in Singapore and the 20th Asian Snooker Championships in India were all postponed because of SARS.

Not just single event competitions, but also multi-event Games were affected by SARS. For instance, Hong Kong and other SARS-affected countries were originally banned from attending the 2003 Special Olympics World Summer Games in Ireland because of contingency measures taken to tackle the SARS problem. It is extremely uncommon for a Government, rather than an event organiser, to limit participation in a sporting event. After long debates and explanations, on 9 June, 2003, the Irish Government finally rescinded and allowed the Hong Kong team to attend the Games. However, a condition was imposed requiring the Hong Kong athletes to attend a 10-day quarantine training camp in a city free from SARS. The original decision was undoubtedly a difficult one. It might have been easier if the decision makers had been provided with the most up-to-date, complete and appropriate information about SARS.

As far as the sports physician is concerned, adequate and correct knowledge is necessary to effectively address any contagion from the perspective of prevention, early recognition and timely control of spread. Appropriate hygienic measures should be taken during sports training and competition, but it may not be necessary to suspend all sports activities, as happened in some settings during the 2003 SARS outbreak. The purpose of this paper is, therefore, to summarise the most current and appropriate information about SARS and its relationship to sports. Most of the information regarding SARS was gathered from WHO's publication. ${ }^{[1]}$ Competition cancellation information was retrieved from the respective sport associations' web sites. The rest of the information was mostly searched in Medline database with keywords: 'SARS', 'exercise', 'upper respiratory infections', ‘immune system' and 'mask'.

\section{What is Severe Acute Respiratory Syndrome (SARS)?}

SARS is a serious infectious disease that is associated with a novel coronavirus. ${ }^{[2-5]}$ SARS evolved 
into a global outbreak in March, 2003. ${ }^{[6-8]}$ In November, 2002, many cases of highly infectious and severe atypical pneumonia of unknown origin were noted in Guangdong Province in Southern China. In retrospect, the clinical features fit into the WHO case definition of SARS; however, it was not reported widely at that stage. SARS was first recognised in Hong Kong in late February, 2003. ${ }^{[9,10]}$ The index case, a doctor from southern China, had been unwell before travelling to Hong Kong. He was admitted to one of the public hospitals in Hong Kong with symptoms of atypical pneumonia. Immediately an outbreak was triggered, firstly in the hospital and later spreading widely throughout the community.

On 12 March, 2003, the WHO issued a global SARS alert. ${ }^{[8]}$ The WHO subsequently received reports of the syndrome from China, Singapore, Vietnam, Canada, the US and Germany. On 21 March, 2003, the WHO issued a preliminary clinical description of SARS. ${ }^{[11]}$ According to the description, the majority of SARS patients were previously healthy adults aged between 25 and 70 years. All patients presented with high fever $\left(>38^{\circ} \mathrm{C}\right)$, sometimes associated with chills, rigor, malaise, myalgia and other respiratory symptoms. The mortality rate was high, reaching $20 \%$. The literature to date suggests that SARS is associated with a novel coronavirus.

The accepted case definition of SARS is that proposed by the WHO and adopted by the US Center of Disease Control and Prevention (CDC). Current criteria for defining a case include clinical data, epidemiological data and laboratory tests. According to the CDC, the SARS case definition was revised on 23 May, 2003, with the clinical criteria being categorised as: (i) asymptomatic; (ii) mild respiratory illness; (iii) moderate respiratory illness (fever $>38^{\circ} \mathrm{C}$, cough, dyspnoea or hypoxia); or (iv) severe respiratory illness (additional radiological evidence of pneumonia or respiratory distress syndrome).
Epidemiological criteria include close contact with SARS cases or travel to an area with community transmission of SARS. Laboratory criteria have been added as evidence of infection with SARSassociated coronavirus (SARS-CoV). 'Probable' cases refer to those meeting the clinical criteria for severe respiratory illness of unknown aetiology and satisfying the epidemiological criteria. 'Suspect' cases refer to those meeting the clinical criteria for moderate respiratory illness of unknown aetiology and satisfying the epidemiological criteria.

The mean incubation period of the SARS virus is 4-6 days and $95 \%$ of patients experience the onset of symptoms within 14.22 days of infection. ${ }^{[1]} \mathrm{Pa}-$ tients with SARS usually present with high fever (temperature $>38^{\circ} \mathrm{C}$ ), dry cough, chills and rigor, and prodromal symptoms (malaise, myalgia, headache and dizziness). ${ }^{[2,9,10,12]}$ The relative frequencies of all reported symptoms vary slightly in different case clusters.

In the first reported SARS case series, Lee et al. ${ }^{[9]}$ reported that all patients presented with fever (temperature $>38^{\circ} \mathrm{C}$ for $>24$ hours) and a majority with chills and rigors (73\%), prodromal symptoms (50-60\%) and coughing (57\%). ${ }^{[9]}$ Productive cough, sore throat, coryza, nausea and vomiting, and diarrhoea were less common symptoms. Based on their data, Lee et al. ${ }^{[9]}$ proposed that the presentation of SARS was triphasic. The first phase, termed the viral replication phase, occurred in the first week with most patients presenting with fever, myalgia and chills. As the disease progressed into second week, $70 \%$ of the patients developed early immune response and cytokines were found in the blood stream. In this immune hyperactive phase, there was significant lung destruction and patients began to develop respiratory symptoms and observable chest radiographic changes. In the third week, patients entered the pulmonary destruction phase, which clinically resembled acute respiratory distress syndrome. Canadian data suggest that the earliest symp- 
toms are fever, prodromal symptoms, cough or dyspnoea and diarrhoea. ${ }^{[2]}$ From the outbreak in Amoy Gardens in Hong Kong, Peiris et al. ${ }^{[13]}$ found that many patients developed recurrent fever (85\%) and watery diarrhoea $(73 \%)$.

In general, physical examination on admission will show high temperature $\left(>38^{\circ} \mathrm{C}\right.$, generally ranging from $35-40.3^{\circ} \mathrm{C}$ ). Tachycardia, tachypnoea and borderline low blood pressure may be observed. Oxygen saturation level on normal air condition may be at borderline situation. Inspiratory crackles are usually heard at the base of the lung but wheezing is an uncommon finding. Rash, lymphadenopathy and purpura are rare.

\section{Mode and Risk of Transmission in Sports}

The coronavirus is one of the two most common pathogens for upper respiratory tract infection (URTI) ${ }^{[14]}$ and it is also the most probable pathogen for SARS. ${ }^{[4]}$ Transmission methods may, therefore, be similar for both infections. The WHO has reported that SARS is not airborne but is carried in virusladen droplets. ${ }^{[1]}$ This suggests that transmission is possible when aerosolised viral particles come into contact with the susceptible host's mucous membranes, most commonly the nose, but also with the mouth and eyes. The virus has been found to be stable in faeces (and urine) at room temperature for at least 1-2 days. ${ }^{[15]}$ Transmission through a defective sewage system was, in fact, proven in the case of the outbreak at Amoy Gardens Estate in Hong Kong. ${ }^{[16]}$ The SARS virus has been reported as occurring in saliva, tears and urine. ${ }^{[1]}$ At the time of writing, no evidence of the SARS virus in a patient's sweat has been reported. Nevertheless, it is still reasonable to assume that the SARS virus may be present in a patient's sweat as it is in other bodily fluids. As summarised by the WHO, ${ }^{[1]}$ the SARS-
$\mathrm{CoV}$ has been isolated after 36 hours from seating, paper, a Formica surface, a plastered wall; after 72 hours from a plastic surface and stainless steel; and after 96 hours on a glass slide. It is, therefore, possible that the virus can be transmitted by hands that have been in contact with these infected surfaces.

Participation in sports training and competition may further add to the above list of possible transmission pathways. Sharing sporting equipment and practice surfaces can be another potential means of transmission. SARS-infected bodily fluids and respiratory secretions can contaminate sporting equipment and practice surfaces. Close personal contact during training and competition in contact sports (wrestling, judo, basketball, etc.) can further transmit SARS from person to person.

A crowded changing room where dense steam and vapour is generated from hot showers can be dangerous in the sense that aerosolised viral particles can be transmitted from any viral carrier to the whole team. This is the most probable transmission pathway of the outbreak in Amy Gardens, Hong Kong. Steam and vapour enhance the floating time of the virus-carrying droplets. ${ }^{[1]}$

Frequent travel may further increase the probability of transmission in sports environments. Staying in relatively crowded aircraft or vehicles with poor ventilation can be risky if there is an infected person travelling with the team. However, the $\mathrm{WHO}^{[17]}$ reported on 23 May, 2003, that symptomatic probable SARS cases on only four flights have been associated with possible transmission onboard. Olsen et al. ${ }^{[18]}$ concluded that SARS may occur on an aircraft when infected persons travel during the symptomatic phase of illness. Therefore, it is still advisable to take precautions to prevent possible transmission during flights. 


\section{Preventive Measures}

\subsection{Avoiding Contact}

Avoiding contact with the virus is the ultimate way to prevent infection. Possible measures range from avoiding unnecessary contact with people, especially those who are infected, wearing masks in high-risk areas to applying sound personal hygiene practice.

Daily monitoring of body temperature before practice will help to identify infected athletes within the team. Fever has been identified as one of the major symptoms of SARS. ${ }^{[4]}$ It is generally believed that SARS patients will become infectious only after the development of symptoms. It has also been found that SARS is most infectious on the tenth day of infection and it is rare for patients who have been isolated within 5 days of becoming ill to transmit infection. ${ }^{[1]}$ Hence, isolating individuals with fever will be one of the most effective and practical ways to avoid contact. Athletes experiencing fever should not be allowed to train and immediate medical advice should be sought.

\subsection{Personal Hygiene}

Maintaining personal hygiene is another way to reduce the risk of infection. Based on the fact that the SARS virus can be found in excreta, ${ }^{[15]}$ hand washing after using the bathroom should be strictly applied. Frequent hand washing, especially after touching public facilities and before rubbing one's own nose, mouth and eyes, are effective in preventing the transfer of the virus from contaminated surfaces to the mucous membranes. Covering the mouth and nose while sneezing and coughing is also essential. Used tissue paper should be treated properly and put in a covered rubbish bin or flushed down the toilet. Universal precautions ${ }^{[19]}$ should be applied to the handling of blood and bodily fluids (including vomitus, nasal secretions, etc.).
Athletes with urinary and bowel stomas or difficulty with bladder and bowel control should pay special attention to sealing off any leakage before exercise, particularly for water sport events.

At time of writing, there have been no reports on the survival of the SARS virus in patient's sweat; however, sweat should be treated as a possible means of transmitting SARS. Showering after training is, therefore, recommended to help to control the potential spread. In sports activities involving close contact (e.g. wrestling), showering before training and competition is also recommended. ${ }^{[20]}$

Minor abrasions should be cleaned with soap and water before applying antiseptic cream and bandaging to prevent entry of the virus. Clothing used during practice should be changed and laundered everyday. Sporting equipment should be sanitised with diluted bleach (1 part bleach in 99 parts water) daily. Similarly, practice surfaces should be cleaned with diluted bleach both before and after training.

Other personal hygiene practices should include special precautions during meals to prevent cross contamination when sharing food. The use of serving utensils should be encouraged. Before serving, all food should be properly covered to minimise any possible contamination.

\subsection{Improving Immunity}

Resistance to infection depends upon the general state of health of an individual as well as the individual's innate and adaptive immunological competence. ${ }^{[21]}$ Other factors that influence susceptibility include the dose and virulence of the infecting micro-organism. ${ }^{[8]}$ As SARS is an extremely virulent virus, it is important to enhance the immune system to reduce the risk of infection. At the time of writing, no study has been published investigating the relationship between exercise, immunity and SARS. Therefore, studies examining the relationship between URTI and exercise may improve our 
understanding of the relationship between SARS and exercise.

There is a current consensus that moderate exercise can enhance immune function and thus resistance to viral infection. Shephard ${ }^{[22]}$ and Peters ${ }^{[23]}$ have stated that a high level of physical conditioning had, in a few carefully controlled recent studies, provided evidence of a lower incidence of infection symptoms and chronic immunomodulation helping to increase resistance to infection. Nieman et al. ${ }^{[24]}$ have noted that 45 minutes of exercise five times per week at $60 \%$ of the heart rate reserve reduced the duration of respiratory symptoms but did not affect the incidence of URTI in 25- to 45-year-old women. In a later study, Nieman et al. ${ }^{[25]}$ investigated the relationship between poor immune function and low levels of physical activity in a group of elderly women. They concluded that any benefit of regular physical activity was more obvious in this group. In this study, they found that among 67- to 85-year-old women, the incidence of URTI was lowest in a highly conditioned subgroup, intermediate in a subgroup of regular walkers and highest in callisthenic and sedentary control subgroups. They suggested that $\mathrm{T}$ cells were the major component of the immune system to be altered with age and that a highly conditioned elderly woman might have $\mathrm{T}$ cells that function at levels above their sedentary counterparts but still somewhat lower than those of young women. On the other hand, natural killer cell activity was considerably greater in highly conditioned elderly women than in either sedentary elderly or young women. Hence, continuous regular moderate exercise can boost the immune systems of elderly women.

One concern about SARS and physical training is that there are reports that a small number of SARS patients were asymptomatic. ${ }^{[1]}$ This group consisted largely of elderly patients. If an individual is training with another individual who has contracted SARS but without obvious symptoms (fever), the risk will be very high. Fever is a consequence of the immune system's response to eradicate the invading virus. Therefore, it is usually only those who have weak immune systems, such as the elderly, ${ }^{[26]}$ who will not have an immune response to the invading virus. Those who exercise regularly will have a better immune system and will have a normal immune response. ${ }^{[26]}$ Therefore, exercising with someone who is active and has no symptoms of SARS will probably constitute a low risk of contracting SARS.

On the other hand, Nieman et al. ${ }^{[24]}$ stated that runners training $>96 \mathrm{~km} /$ week doubled their odds for sickness (URTI) compared with those training $<32 \mathrm{~km} /$ week. It has been suggested that athletes engaging in marathon-type events and/or engaged in very heavy training are at increased risk of URTI. ${ }^{[27]}$ This may due to the fact that acute exercise (a single bout of intense exercise) temporarily decreases the activity of several of the immune system's cellular components and increases athletes' susceptibility to viruses. ${ }^{[28]}$ However, Shephard, ${ }^{[22]}$ in his more recent review, stated that in terms of the adverse effects on the immune system due to very heavy exercise and training, all of the expected epidemiological criteria associated with a cause and effect relationship have not been met in earlier studies. Therefore, very high-intensity exercise may not be the causal factor of the lowered immune system.

This controversy may, in part, be due to the variation in defining 'heavy or very high-intensity' exercise. Weidner ${ }^{[29]}$ summarised that people who exceeded their individual exercise limit (activity frequency, intensity and duration) might be fostering infection. For competitive athletes, it is impossible for them to train at low to moderate intensity, but in order to avoid the adverse effects on the immune system due to high-intensity workouts, athletes' training must be systematically monitored to prevent training beyond individual limits and chronic overtraining. 
Nieman $^{[27]}$ also concluded that following acute bouts of prolonged high-intensity endurance exercise, several components of the immune system are suppressed for several hours. This has led to the concept of the 'open window' theory, which was described as the 1- to 9-hour period following prolonged endurance exercise when the host's defences are decreased and the risk of URTI is increased. During this 'open window' period, athletes should be advised to remain isolated from all the possible sources of infection.

In addition to regular exercise, there are other means to improve immunity against possible SARS infection. They include diet, proper rest and reduced psychological stress. An efficient immune system requires a number of nutrients to sustain itself. Essential amino acids, the essential fatty acid - linoleic acid, retinol (vitamin A), folic acid, pyridoxine (vitamin B6), cyanocobalamin (vitamin B12), ascorbic acid (vitamin C), tocopherol (vitamin E), zinc, copper, iron and selenium have all been found to be beneficial to the immune system. ${ }^{[30]}$ Other nutrients that may help to maintain a healthy immune system include arginine, glutamine, omega-3-fatty acids and nucleotides. ${ }^{[31,32]}$ Sleep deprivation is known to have a detrimental effect on the immune system. ${ }^{[33]}$ Getting enough sleep and proper rest is, therefore, also important in ensuring an efficient immune system. Furthermore, psychological stress and depression were found to be associated with immunosuppression. ${ }^{[34,35]}$ A 'stress, cytokine, depression' model has been proposed as a biological pathway to explain the link between stressful life events and depression. ${ }^{[35]}$ It is generally agreed that the stress associated with competition may make athletes more susceptible to infectious illnesses. ${ }^{[36]}$ Declines in immune function can be related to heavy training prior to competition, ${ }^{[23,24]}$ psychological stress related to competition, ${ }^{[37]}$ the exposure to extremes of heat and cold, sleep deprivation and time-zone shifts. ${ }^{[38,39]}$

\section{Exercise During and After Contracting SARS}

Whether exercise is recommended during and after contracting SARS is an interesting topic for discussion. During the acute phase of the SARS disease, it is almost impossible for the patient to perform any exercise in the presence of severe symptoms that may include fever (temperature, $>38^{\circ} \mathrm{C}$ for $>24$ hours), rigor, dry cough, dyspnoea, malaise, headache and hypoxaemia. ${ }^{[11]}$ Relative rest is, therefore, recommended during this phase of the disease.

Carefully prescribed exercise has been found to be an essential part of treatment or rehabilitation programme for various chronic diseases such as cardiac disease, chronic obstructive pulmonary disease, hypertension and asthma. ${ }^{[23,29,36,40]}$ It is, therefore, expected that an individually prescribed exercise programme that aims to improve cardiorespiratory function and general wellbeing, will also be beneficial to stabilised SARS patients. A muscle strengthening programme may be prescribed prior to cardiovascular training. After weeks of bed rest, muscle condition may decrease significantly. ${ }^{[40]}$ Therefore, muscle strengthening programmes, especially for lower body muscles are required before recovering patients can perform other locomotory rehabilitation programmes. However, extra attention should be given to the possible presence of any postviral fatigue syndrome. This is the prolonged period of debilitation sometimes observed during the recovery phase from an apparent viral infection. ${ }^{[24]}$ Although there has been no report to date, of any postviral fatigue syndrome in relation to SARS, the risk of an extended clinical course resulting from attempts to work through this syndrome should be noted. ${ }^{[38]}$ 


\section{Exercise with a Mask}

During the SARS outbreak in Hong Kong, children were required to wear surgical masks during school lessons. This was a safety measure imposed by the Hong Kong Special Administrative Region Government. However, should they wear surgical masks for physical education (PE) lessons? Before answering this question, there are several aspects to be considered.

\subsection{Safety Concerns}

A mask serves the function of blocking the release of disease-causing aerosols from the patient to the external air space when they speak, exhale, cough or sneeze; and stopping or blocking the disease-causing aerosols being transferred to healthy people when they inhale. Therefore, the surgical mask must be able to inhibit aerosol penetration. McCullough et al. ${ }^{[41]}$ stated that the penetration rate of aerosols through a surgical mask depended on the flow rate and the type of organism in the aerosols. When Mycobacterium abscessus and Bacillus subtilis were assessed at a high flow rate $(85 \mathrm{~L} / \mathrm{min})$, there was significantly higher penetration than what was seen at a low flow rate $(45 \mathrm{~L} / \mathrm{min})$. The surgical mask was much less efficient in blocking aerosols than was the N95 mask. ${ }^{[11]}$ The surgical mask with a filter had a $25 \%$ penetration rate of sub-micrometresized aerosols at a flow rate of $5 \mathrm{~L} / \mathrm{min}$ to $70 \%$ at $100 \mathrm{~L} / \mathrm{min} .{ }^{[42]}$ The penetration rate through surgical masks can be well over $25 \%$ when the children are working or exercising at moderate or maximal intensity. The maximal ventilation rate for children aged $11.2 \pm 1.4$ years (in Hong Kong) has been found to be about $46.7 \pm 10.1 \mathrm{~L} / \mathrm{min}$ for girls and $50.3 \pm 11.0$ $\mathrm{L} / \mathrm{min}$ for boys (unpublished data). Therefore, protection afforded by surgical masks may be minimal.

Reaerosolisation cannot be neglected when exercising with a mask. Wang et al. ${ }^{[43]}$ and Willeke and Qian $^{[44]}$ indicated that some reaerosolisation
$(<0.1 \%)$ was possible in N92 masks during violent sneezing or coughing. Therefore, when using a surgical mask, reaerosolisation of the trapped virus is possible under continuous high flow rate during exercise.

\subsection{Effect on Exercise}

Wearing a mask incurs some penalties associated with the interference between wearers and the environment. Johnson et al. ${ }^{[45]}$ noted that workers wearing masks could not work as long or as hard as they could when not wearing masks. Such phenomena may also occur in exercise. Lerman et al. ${ }^{[46]}$ found that with the increase in inspiratory resistance due to wearing a mask during exercise testing, a significant decrease in physical performance and tidal volume, an increase in the ratio of inspiratory to expiratory time, peak inspiratory pressure and increased $\mathrm{CO}_{2}$ retention were observed. They concluded that difficulty in inspiration was significantly correlated with inspiratory resistance and seemed to be the main reason for cessation of effort. Wilson and Raven ${ }^{[47]}$ also noted that wearing of respirator masks reduced forced vital capacity by an average of $11.6 \%$ $(0.65 \mathrm{~L})$; forced expiratory volume in 1 second by $7.3 \%(0.33 \mathrm{~L})$ and maximum voluntary ventilation in 15 seconds by $7.4 \%(12.4 \mathrm{~L} / \mathrm{min})$. They hypothesised that the difference in peak inspired flow with and without the respirator was the best predictor of performance time with the respirator during an endurance walk to exhaustion. Therefore, the resistance of the mask results in a detrimental effect on exercise performance, especially at maximal loading.

One study found a statistically significant decrease in maximal oxygen uptake $\left(\dot{\mathrm{V}}_{2 m a x}\right)$ for participants wearing respirator masks compared with those without masks. ${ }^{[45]}$ The authors also found that the lactate and ventilation threshold were not affected by the mask condition. Therefore, masks may only cause significant impairment of exercise at 
intensities $>80-85 \%$ of $\dot{\mathrm{VO}}_{2 \max }$ (at about the anaerobic threshold level). ${ }^{[48]}$

In summary, taking the safety issue and effects on exercise capacity into consideration, children can only work or exercise at their submaximal level, below the anaerobic threshold, if they are wearing surgical masks. However, there are still some other factors that have to be considered, such as air temperature and relative humidity, before suggesting that children exercise with masks.

\subsection{How Does SARS Affect School Physical Education Programmes?}

After the outbreak of SARS in early March, the Education Authority of Hong Kong announced that all primary and secondary school classes were suspended in late March, 2003. All school children were advised to stay home and avoid physical contact with others. Seven weeks later, when SARS was under control, secondary and primary school classes were resumed on 16 and 23 May, 2003, respectively. The local Education Authority mandated that all students and teachers should wear masks all the time in schools.

A survey was conducted by a local Hong Kong University to determine how the school PE and extra-curricular activity programmes were being affected after classes had resumed. Questionnaires were sent out to 400 secondary and 712 primary school PE teachers. Within 1 week, 276 secondary and 530 primary school PE teachers had responded. Table I shows a brief summary of the findings concerning the special arrangements made by the schools.

In addition, the survey further investigated the perceptions of the PE teachers on the influences on the PE programme of the SARS preventive measures in school settings. Half (50\%) of the secondary and $46 \%$ of the primary school PE teachers reported adjustments to their normal PE curriculum. Most curriculum time involved changes to individual
Table I. Special arrangements by the schools in Hong Kong after the outbreak of Severe Acute Respiratory Syndrome

\begin{tabular}{lll}
\hline Special arrangements & $\begin{array}{l}\text { Primary } \\
\text { schools (\%) }\end{array}$ & $\begin{array}{l}\text { Secondary } \\
\text { schools (\%) }\end{array}$ \\
\hline $\begin{array}{l}\text { Physical education classes } \\
\text { suspended }\end{array}$ & 23 & 13 \\
$\begin{array}{l}\text { Extra-curricular activities } \\
\text { suspended }\end{array}$ & 85 & 80 \\
$\begin{array}{l}\text { Swimming classes suspended } \\
\begin{array}{l}\text { Students required to wear masks } \\
\text { in physical education classes }\end{array}\end{array}$ & 92 & 94 \\
\hline
\end{tabular}

sports, such as badminton and table-tennis. In order to avoid physical contact among the students, most major team sports like basketball and soccer were suspended during PE lessons and after school activities. As a result, a noticeable drop in students' physical activity levels was indicated by PE teachers. Based on subjective observation, secondary and primary school PE teachers reported an average $32 \%$ and $40 \%$ decline in physical activity levels, respectively. Over $50 \%$ of the respondents revealed that PE apparatus and equipment was not clean enough and there were insufficient staff members to clean up such apparatus before a PE class. Moreover, $25 \%$ of the PE teachers revealed that the changing rooms were unclean. Over half (53\%) of secondary and $47 \%$ of primary school PE teachers were worried about their students being infected during PE classes.

\section{Conclusion}

SARS is a highly infectious disease, caused by the novel coronavirus, with possible severe clinical sequelae. Not only has it put enormous strain on the healthcare system worldwide, it has also affected the physical, psychological and social behaviours of affected communities across the globe. Without exception, sports activities and sports medicine practices have also been affected. With adequate knowledge of SARS and common sense, we stand a better chance of avoiding the SARS panic spreading worldwide. 
The old proverb, 'prevention is better than cure', still holds true. After all, SARS is basically another viral infection, most likely spread by infectious droplets or direct contact. Good personal hygiene measures and strengthening the body's immune system are important issues.

If an athlete has been exposed to the virus or has suspected symptoms, early recognition and prompt isolation are important basic measures. Active ongoing research on the development of vaccines and the most effective treatment is booming.

Most likely, the impact of SARS on sport will go far beyond just the possible need of medical treatment of SARS patients. Some issues, like pre-event screening for infection or for symptomatic individuals, sport events planning to allow quarantine measures, special travel arrangements and venue designs with good ventilation and filtering systems, are areas that need to be reviewed.

\section{Acknowledgements}

The authors would like to thank Dr Trisha Leahy, of the Technical Services Division, Hong Kong Sports Development Board, for her valuable comments on preparing the manuscript. The authors received no extra funding for preparation of this review and have no conflicts of interests relevant to the contents of this review.

\section{References}

1. Department of Communicable Disease Surveillance and Response, World Health Organization. Consensus document on the epidemiology of severe acute respiratory syndrome (SARS). Geneva: World Health Organization, 2003

2. Booth CM, Matukas LM, Tomlinson GA, et al. Clinical features and short-term outcomes of 144 patients with SARS in the greater Toronto area. JAMA 2003; 289 (21): 2801-9

3. Ksiazek TG, Erdman D, Goldsmith CS, et al. A novel coronavirus associated with severe acute respiratory syndrome. N Engl J Med 2003; 348 (20): 1953-66

4. Peiris JS, Lai ST, Poon LL, et al. Coronavirus as a possible cause of severe acute respiratory syndrome. Lancet 2003; 361 (9366): 1319-25

5. Drosten C, Gunther S, Preiser W, et al. Identification of a novel coronavirus in patients with severe acute respiratory syndrome. N Engl J Med 2003; 348 (20): 1967-76
6. Update: outbreak of severe acute respiratory syndrome: worldwide, 2003. MMWR Morb Mortal Wkly Rep 2003; 52 (13): 269-72

7. Global surveillance for severe acute respiratory syndrome (SARS). Wkly Epidemiol Rec 2003; 78 (14): 100-19

8. Severe acute respiratory syndrome (SARS). Wkly Epidemiol Rec 2003; 78 (12): 81-3

9. Lee N, Hui D, Wu A, et al. A major outbreak of severe acute respiratory syndrome in Hong Kong. N Engl J Med 2003; 348 (20): 1986-94

10. Tsang KW, Ho PL, Ooi GC, et al. A cluster of cases of severe acute respiratory syndrome in Hong Kong. N Engl J Med 2003; 348 (20): 1977-85

11. Preliminary clinical description of severe acute respiratory syndrome. MMWR Morb Mortal Wkly Rep 2003; 52 (12): 255-6

12. So LKY, Lau ACW, Yam LYC, et al. Development of a standard treatment protocol for severe acute respiratory syndrome. Lancet 2003; 361 (9366): 1615

13. Peiris JSM, Chu CM, Cheng VCC, et al. Clinical progression and viral load in a community outbreak of coronavirus-associated SARS pneumonia: a prospective study. Lancet 2003; 361 (9371): 1767-72

14. Heath GW, Macera CA, Nieman DC. Exercise and upper respiratory tract infections: is there a relationship? Sports Med 1992; 14 (6): 353-65

15. World Health Organization. First data on stability and resistance of SARS coronavirus XXX WHO laboratory network [online]. Available from URL: www.who.int/csr/sars/survival-2003-05-04 [Accessed 2003 May 19]

16. World Health Organization. WHO environmental health team reports on Amoy Gardens [online]. Available from URL: http:/ /www.info.gov.hk/dh/ap.htm [Accessed 2003 May 25]

17. World Health Organization. Summary on SARS and air travel [online]. Available from URL: http://www.who.int/csr/sars/ travel/airtravel/en/ [Accessed 2003 May 25]

18. Olsen SJ, Chang HL, Cheung TY, et al. Transmission of the severe acute respiratory syndrome on aircrafts. N Engl J Med 2003; 349 (25): 2416-22

19. Perry C, Barnett J. Practices and procedures for universal precautions. Emerg Nurse 1998; 6 (7): 24-32

20. Howe WB. Preventing infectious disease in sports. Phys Sports Med 2003; 31 (2): 23-9

21. Clarke M. The constructs 'stress' and 'coping' as a rationale for nursing activities. J Adv Nurs 1984; 9: 267-75

22. Shephard RJ. Special feature for the olympics: effects of exercise on the immune system: overview of the epidemiology of exercise immunology. Immunol Cell Biol 2000; 78 (5): 485-95

23. Peters EM. Exercise, immunology and upper respiratory tract infections. Int J Sports Med 1997; 18 Suppl. 1: S69-77

24. Nieman DC, Johanssen LM, Lee JW, et al. Infectious episodes in runners before and after the Los Angeles marathon. J Sports Med Phys Fitness 1990; 30: 316-28

25. Nieman DC, Henson DA, Gusewitch G, et al. Physical activity and immune function in elderly women. Med Sci Sports Exerc 1993; 25 (7): 823-31

26. Yan H, Kuroiwas A, Tanaka $\mathrm{H}$, et al. Effect of moderate exercise on immune senescence in men. Eur J Appl Physiol 2001; 86: 105-11 
27. Nieman DC. Upper respiratory tract infections and exercise. Thorax 1995; 50 (12): 1229-31

28. Shephard RJ, Shek PN. Exercise, immunity, and susceptibility to infection-A J-shaped relationship? Phys Sportsmed 1999; 27 (6): 47-71

29. Weidner TG. Literature review: upper respiratory illness and sport and exercise. Int J Sports Med 1994; 15: 1-9

30. Calder PC, Kew S. The immune system: a target for functional foods? Br J Nutr 2002; 88 (2): S165-77

31. Newsholme P, Lima MM, Procopio J, et al. Glutamine and glutamate as vital metabolites. Braz J Med Biol Res 2003; 36 (2): $153-63$

32. Singh R, Gopalan S, Sibal A. Immunonutrition. Indian J Pediatr 2002; 69 (5): 417-9

33. Ozturk L, Pelin Z, Karadeniz D, et al. Effects of 48 hours sleep deprivation on human immune profile. Sleep Res Online 1999; 2 (4): $107-11$

34. Leonard B. Stress, depression and the activation of the immune system. World J Biol Psychiatry 2000; 1 (1): 17-25

35. Maddock C, Pariante CM. How does stress affect you? An overview of stress, immunity, depression and disease. Epidemiol Psichiatr Soc 2001; 10 (3): 153-62

36. Brenner IK, Shek PN, Shephard RJ. Infection in athletes. Sports Med 1994; 17 (2): 86-107

37. Totman R, Kiff J, Reed SE, et al. Predicting experimental colds in volunteers from different measures of recent life stress. Psychosom Res 1980; 24: 155-63

38. Shephard RJ. Immune changes induced by exercise in an adverse environment. Can J Physiol Pharmacol 1998; 76: 539-46

39. Shephard RJ, Shek PN. Immune deficits induced by strenuous exertion under adverse environmental conditions: manisfestation and countermeasures. Crit Rev Immunol 1998; 18: 545-68

40. Yamamoto T, Sekiya N, Miyashita S, et al. Gender differences in effects of 20 days horizontal bed rest on muscle strength in young subjects. J Gravit Physiol 1997; 4 (1): S31-6
41. McCullough NV, Brosseau LM, Vesley D. Collection of three bacterial aerosols by respirator and surgical mask filters under varying conditions of flow and relative humidity. Ann Occup Hyg 1997; 41 (6): 677-90

42. Chen CC, Willeke K. Aerosol penetration through surgical masks. Am J Infect Control 1992; 20 (4): 177-84

43. Wang Z, Reponen T, Willeke K. Survival of bacteria on respirator filters. Aerosol Sci Technol 1999; 30: 300-8

44. Willeke K, Qian Y. Tuberculosis control through respirator wear: performance of National Institute for Occupational Safety and Health-regulated respirators. Am J Infect Control 1998; 26 (2): 139-42

45. Johnson AT, Dooly CR, Dotson CO. Respirator mask effects on exercise metabolic measures. Am Ind Hyg Assoc J 1995; 56 (5): 467-73

46. Lerman Y, Shefer A, Epstein Y, et al. External inspiratory resistance of protective respiratory devices: effects on physical performance and respiratory function. Am J Ind Med 1983; 4 (6): $733-40$

47. Wilson JR, Raven PB. Clinical pulmonary function tests as predictors of work performance during respirator wear. Am Ind Hyg Assoc J 1989; 50 (1): 51-7

48. Jette M, Thoden J, Livingstone S. Physiological effects of inspiratory resistance on progressive aerobic work. Eur J Appl Physiol Occup Physiol 1990; 60 (1): 65-70

Correspondence and offprints: Raymond C.H. So, Sports Science Department, Hong Kong Sports Development Board, Sports Institute, Shatin, 25 Yuen Wo Rd, NT, Hong Kong.

E-mail: raymonds@hksi.org.hk 